\title{
Contact Stress Analysis of Tapered Interference Fit for the Cantilevered Axle
}

\author{
Shufen Xiao ${ }^{1, a^{*}}$, Xueqi Jiang ${ }^{2, b}$ and Xiwen $\mathrm{Li}^{3, \mathrm{c}}$ \\ ${ }^{1,3}$ School of Computer \& Information Science, Hubei Engineering University, Xiaogan, Hubei, China \\ ${ }^{2,3}$ School of Mechanical Science \& Engineering, Huazhong University of Science \& Technology, \\ Wuhan, Hubei, China \\ a874883176@qq.com, b674302602@ qq.com, 'xiwenli@hust.edu.cn
}

Keywords: Contact stress; Tapered interference fit; Equivalent stress; FEM method.

Abstract. By means of mechanic analysis, the contact stress analysis along the axial direction of the tapered interference fit was conducted, and it was compared with the FEM analysis of 3 modes of different load, namely, displacement load, pressure load, and offset load. Results shows that: the position of maximum contact stress of the tapered interference fit is at large end of the interference fit; the value of the middle section from calculation coincides well with the values from FEM method; and for the equivalent stress analysis, the values of the middle section of the 3 modes of load coincides well.

\section{Introduction}

Cantilevered axles are frequently employed in equipment for chemical engineering, metallurgy, petroleum, food and environment industries. As for cantilevered axle for the mixing process, it undertakes complicated loads, including dynamic torque to mix the materials, impulse torque resulting from agglomeration of the materials, axial force and radial force from the materials processed, and bending moment resulting from the radial force [1].

To provide reliable performance for the mixing process, the cantilevered axle and the mixing blade should have good connection, and interference fit is the only choice for some application circumstances of heavy load with impulse and dynamic change. Recently, tapered interference fit and its contact stress draw more and more study interests. The effect of interference diameters on contact stress of the tapered interference fit was presented [2]. The effects of structures and press forces on the contact stress were studied as well[3,4]. The effect of correlative geometrical parameters on the radial displacement of the outer race of the tapered interference fit was investigated[5].

The objectives of this study were, to obtain a mathematic model for the contact stress along the axial direction of the tapered interference fit; to perform the FEM analysis of contact stress under different sets; and to compare the analysis from calculation and FEM method.

\section{Contact Stress Model of Tapered Interference and the Analysis}

Model. Set the coordinate system of the tapered interference fit, with $\mathrm{x}$ along the axial direction and $\mathrm{y}$ along the radial direction, as shown in Fig.1.

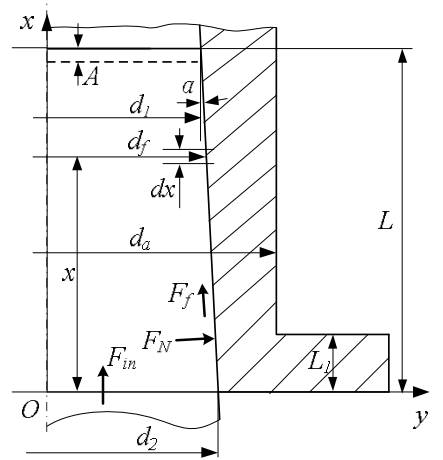

Figure. 1 Contact of the tapered interference fit. 
Take element $\mathrm{dx}$ at location $\mathrm{x}$, the interference diameter $\mathrm{d}_{\mathrm{f}}(\mathrm{x})$ can be expressed as Eq.1:

$d_{f}(x)=d_{2}-2 x \tan \alpha$

where $\mathrm{d}_{2}=$ diameter of the large end of the tapered interference fit; $\alpha=$ half cone angle.

For the element $d x$, assume that it is a cylindrical interference fit. Then the contact stress $\mathrm{p}(\mathrm{x})$ of the element $\mathrm{dx}$ can be expressed as Eq.2:

$$
p(x)=\frac{\delta}{d_{f}(x)\left(\frac{C_{a}}{E_{a}}+\frac{C_{i}}{E_{i}}\right)}
$$

where $\delta=$ magnitude of interference; $\mathrm{C}_{\mathrm{a}}=$ constant of the containing part; $\mathrm{C}_{\mathrm{i}}=$ constant of the internal part; $E_{a}=$ elastic modulus of the containing part; $E_{i}=$ elastic modulus of the internal part. $C_{a}$ and $\mathrm{C}_{\mathrm{i}}$ are can be expressed as Eq.3 \& Eq.4[6]: calculated by the ratio of inner and outer diameters of the containing part of the interference fit and the Poisson's ratio of the containing part:

$$
\begin{gathered}
C_{a}=\frac{1-q_{a}^{2}}{1+q_{a}^{2}}+v_{a} \\
C_{i}=\frac{1+q_{i}^{2}}{1-q_{i}^{2}}+v_{i}
\end{gathered}
$$

where $\mathrm{q}_{\mathrm{a}}=$ ratio of inner and outer diameters of the containing part of the interference fit; $\mathrm{q}_{\mathrm{i}}=$ ratio of inner and outer diameters of the internal part of the interference fit; ${ }_{a}=$ Poisson's ratio of the containing part; $v_{i}=$ Poisson's ratio of the internal part.

Considering the containing part with 2 different outer diameters, $d_{a 1}$ and $d_{a 2}$, set $d_{a}(x)=d_{a 1}$ while $0<\mathrm{x}<\mathrm{L}_{1}$, and $\mathrm{d}_{\mathrm{a}}(\mathrm{x})=\mathrm{d}_{\mathrm{a} 2}$ while $\mathrm{L}_{1}<\mathrm{x}<\mathrm{L}$. If the containing part and internal part have same elastic modulus E and Poisson's ratio, there is Eq.5:

$$
p(x)=\frac{\delta E}{2}\left(\frac{1}{d_{f}(x)}-\frac{d_{f}(x)}{d_{a}^{2}(x)}\right)
$$

For parameters as shown in Table 1, the contact stress of the tapered interference fit along $\mathrm{x}$ can be calculated, and the result is shown in Fig.2.

Table 1. Parameters for the contact stress calculation

\begin{tabular}{clc}
\hline & Parameter & Value \\
\hline$\delta$ & Magnitude of interference & $0.02[\mathrm{~mm}]$ \\
$\mathrm{E}$ & Elastic modulus & $200[\mathrm{GPa}]$ \\
$v_{a}$ & Poisson's ratio of the containing part & 0.3 \\
$v_{i}$ & Poisson's ratio of the internal part & 0.3 \\
$\mathrm{~d}_{2}$ & Diameter of the large end & $60[\mathrm{~mm}]$ \\
$\mathrm{L}$ & Contact length & $100[\mathrm{~mm}]$ \\
$\mathrm{d}_{\mathrm{a} 1}$ & Outer diameter of large section of the containing part & $160[\mathrm{~mm}]$ \\
$\mathrm{d}_{\mathrm{a} 2}$ & Outer diameter of small section of the containing part & $80[\mathrm{~mm}]$ \\
$\mu$ & Friction coefficient of the contact surface & 0.1 \\
\hline
\end{tabular}

Analysis. As shown in Fig.2, different contact position owns different contact stress. There are large contact stress change, at position $\mathrm{x}=20 \mathrm{~mm}$, because of outer diameter change from large section of diameter $160 \mathrm{~mm}$ to small section of diameter $80 \mathrm{~mm}$.

For practical use, if hydraulic pressure method is employed for the tapered interference fit, the outer diameter change of the containing part should be avoided in case of large contact stress change that will bring bad effect to performance of the hydraulic pressure mechanism, and it is bad for the disconnection of the interference fit[6]. 


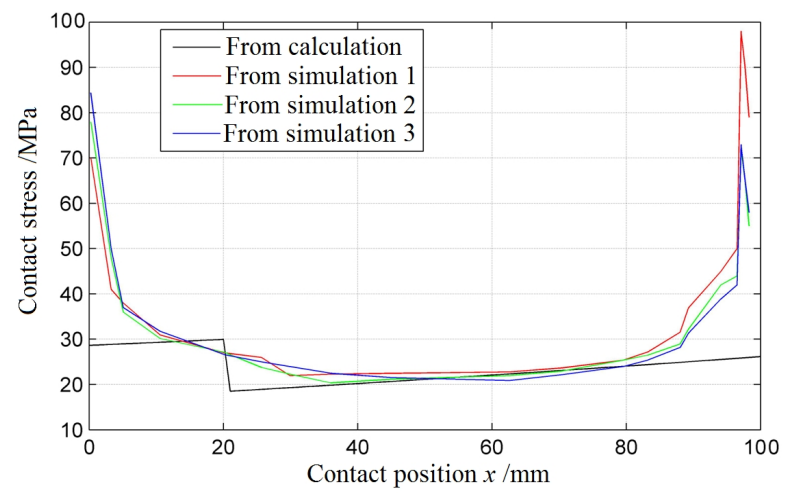

Figure 2. Contact stress from calculation and simulation.

\section{FEM Analysis of Contact Stress}

Modeling \& simulation. By applying FEM method to model and simulate the contact stress along the tapered interference fit surface in ANSYS Workbench.

For simplicity, considering symmetry of the tapered interference fit, quarter of the interference fit was selected for the FEM analysis. Ignoring the effect of threaded hole on contact stress, the 3-D geometric model was built by means of SolidWorks, as shown in Fig.3.

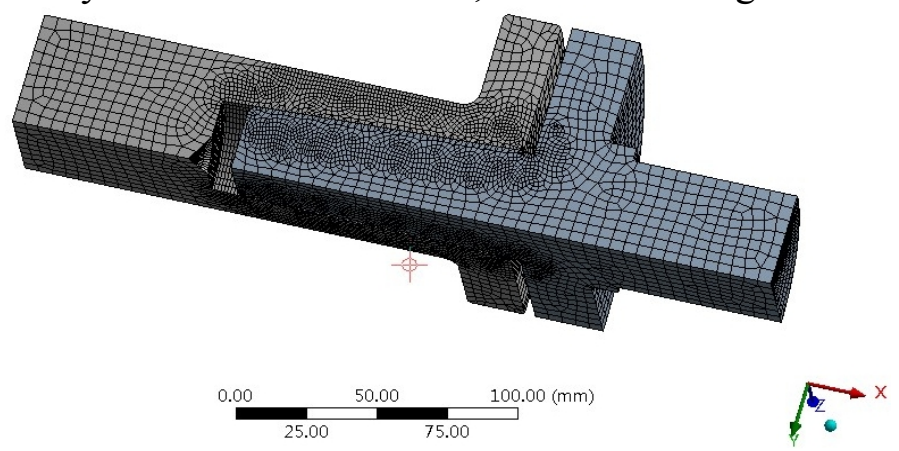

Figure 3. Geometric model of the tapered interference fit.

Import the 3-D geometric model into Static Structural module of the Workbench, and mesh the model by Sweep mode. Set the elastic modulus and Poisson's ration as shown in Table 1.

Set boundary and constraint conditions of the interference fit. Select the quarter section of the model as smooth non-friction symmetrical plane, and both ends of the interference fit as fixed support constraint plane.

Apply load to the tapered interference fit. There are 3 modes of load can be selected as follows: 1) displacement load with $0.01 \mathrm{~mm}$; 2) pressure load with $15.36 \mathrm{KN}$; 3) load through setting offset $0.2 \mathrm{~mm}$ (magnitude of interference $0.02 \mathrm{~mm}$ can be obtained) of the contact surface. The results of simulation of the 3 modes load were defined as simulation 1, simulation 2 , and simulation 3 , respectively.

Set surfaces of containing part and internal part of the tapered interference fit as contact surface and objective surface. Select contact type as friction and friction coefficient 0.1 . Normal Lagrange solver was adopted for the simulation. Then the contact stress distribution of the 3 modes of load can be obtained by simulation, as shown in Fig.4.

Analysis. As shown in Fig.4, the contact stress has the maximum value at the large end of the tapered interference fit surface and the minimum value at the small end of the interference fit with pressure load and load through setting offset (simulations $2 \& 3$ ). While it has the maximum value at the small end of the interference fit surface and the minimum value at the large end of the interference fit with displacement load pressure load and load through setting offset (simulations 1). The maximum values have difference of $25 \%$, but the areas of the maximum values are very small, so these areas cannot represent the overall contact. 

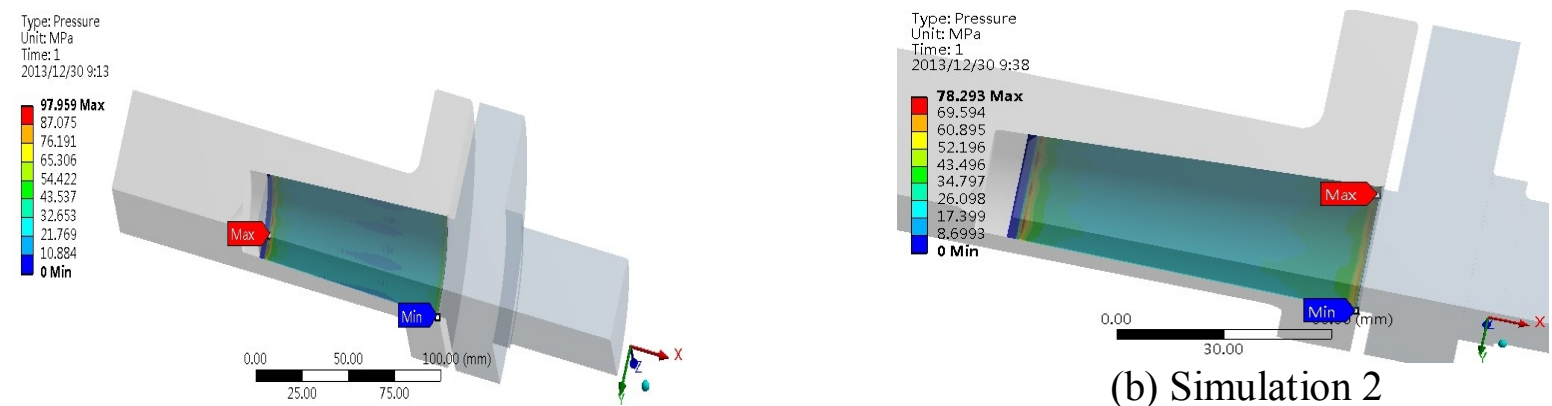

(a) Simulation 1

(b) Simulation 2

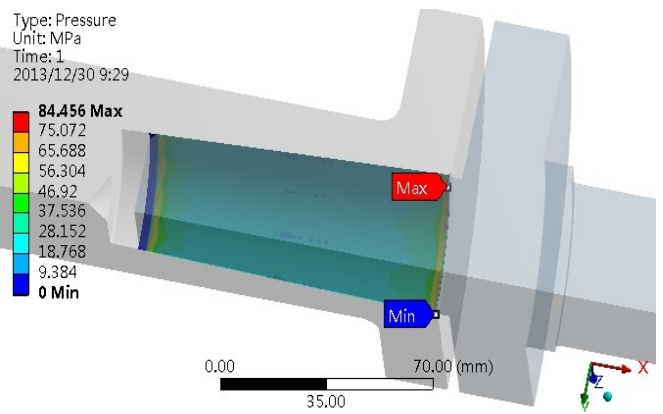

(c) Simulation 3

Figure 4. Contact stress distribution of different modes of load.

For comparison the results from calculation and FEM method, let the contact stress values along contact position come together, as shown in Fig.2. The contact stress change shows that the contact stress values are largely in the range of 20 to $30 \mathrm{MPa}$, and the values from FEM method are higher than that from calculation.

For the purpose of explanation of the conflict regarding maximum position that happens by using different modes of load, equivalent (von-Mises) stress were obtained by FEM method with the same modes of load as well, and the equivalent stress distribution of the simulations were shown in Fig.5.

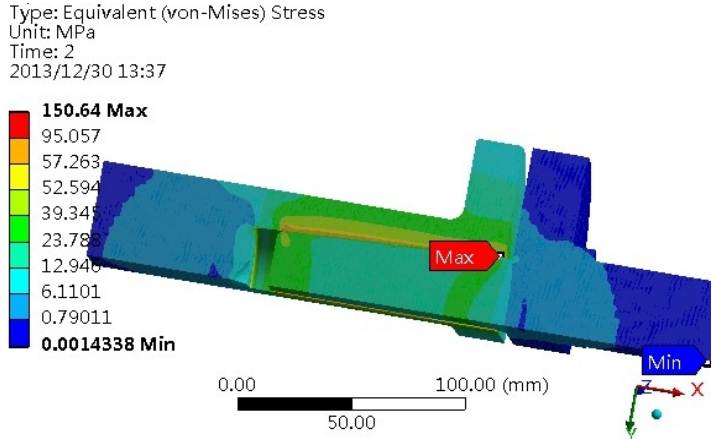

(a) Simulation 1

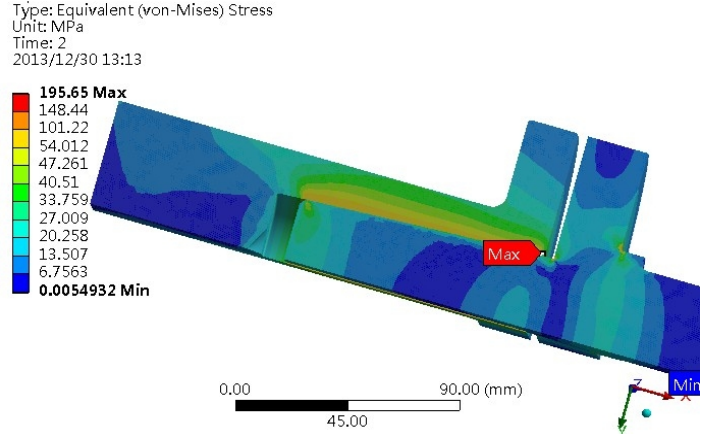

(b) Simulation 2

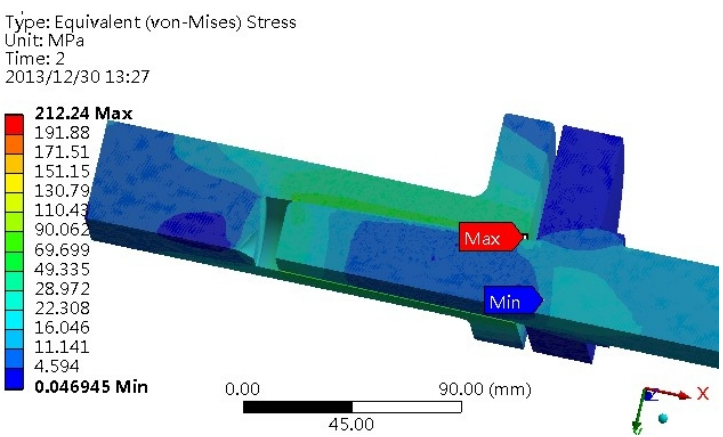

(c) Simulation 3

Figure 5. Equivalent stress distribution of the interference fit. 
From Fig.5, the maximum equivalent stress along contact position all happens at the large end of the tapered interference fit, of which, the maximum value of simulation 1 is about $150 \mathrm{MPa}$, and the maximum values of simulations $2 \& 3$ are about $200 \mathrm{MPa}$.

Discussion. As shown in Fig.2, there is obvious difference of contact stress values obtained from calculation and FEM analysis at both ends of the tapered interference fit of $10 \%$ length of both ends, especially $3 \mathrm{~mm}$ length of both ends. The value of the middle section from calculation coincides well with the values from FEM method.

For the equivalent stress analysis, the contact stress decreases much at both ends of the tapered interference fit and the values of the middle section of the 3 modes of load coincides well. For example, there is only a $1.6 \mathrm{MPa}$ difference at the contact location $\mathrm{x}=60.5 \mathrm{~mm}$.

For practical use of tapered interference fit of the cantilevered axle, the interference fit should undertake more complicated load to meet the connection requirement. The load includes pressure force for the interference, torque for the power transmission, weight of the axle and load, etc. Therefore, torque transmission status and performance should further studied for the tapered interference fit, especially under heavy load circumstance.

\section{Conclusions}

Cantilevered axles are important components in modern manufacturing industry, with tapered interference fit served as connection and load transmission. By means of mechanic analysis, the contact stress analysis along the axial direction of the tapered interference fit was conducted, and it was compared with the FEM analysis of 3 modes of different load. From mechanic analysis and FEM method analysis, the following conclusions can be obtained:

1) The position of maximum contact stress of the tapered interference fit is at large end of the interference fit, and there is large contact stress change if there is large outer diameter change.

2) There is obvious difference of contact stress values obtained from calculation and FEM analysis at both ends of the tapered interference fit of $10 \%$ length of both ends, and the value of the middle section from calculation coincides well with the values from FEM method.

3) For the equivalent stress analysis, the contact stress decreases much at both ends of the tapered interference fit and the values of the middle section of the 3 modes of load coincides well.

\section{References}

[1] K. M. Mohamed, A. G. Gerber, G. A. L. Holloway, 2009 Modelling of Hydrodynamic Forces on a Whirling Mixing Vessel Stirrer Including Fluid-Structure Interaction. Proceedings of the ASME 2009 Pressure Vessels and Piping Division Conference.26-30 July, 2009. Prague, Czech Rebubli.

[2] V. Ramamurti, R. Karthikeyan, Stress analysis of taper locks. Computers \& structures 62(1997): 721-736.

[3] A. Özel, Ş. Temiz, M. D. Aydin, et al. Stress analysis of shrink-fitted joints for various fit forms via finite element method. Materials \& design 26(2005): 281-289.

[4] I. T. Cook, H. Fessler, T. H. Hyde, et al. Assembly stresses in taper-locking shaft couplings Part 1: Photoelastic work. Journal of Strain Analysis for Engineering Design 36(2001) : 25-34.

[5] W.J. Li, \& C.Y. Pan, Engineering approach to static analysis of tapered interference fit. Journal of Mechanical Strength 33(2011): 86-92.

[6] D.Q. Xu, R.W.Sun, Design, calculation and disassembling of interference fit., China Metrology Publishing House ,Beijing, 1992. 